\title{
Desenvolvimento e produção de duas cultivares de cebola irrigadas por gotejamento ${ }^{1}$
}

\author{
Renato C. Vilas Boas ${ }^{2}$, Geraldo M. Pereira ${ }^{3}$, Rovilson J. de Souza ${ }^{4}$, \\ Luciano O. Geisenhoff ${ }^{5}$ \& Joaquim A. de Lima Júnior ${ }^{5}$
}

\begin{abstract}
RESUMO
Objetivou-se, com este trabalho, avaliar o efeito de diferentes tensões da água no solo sobre o desenvolvimento e produção de duas cultivares de cebola irrigadas por gotejamento. O experimento foi conduzido na área experimental do DAG/UFLA, no período de junho a outubro de 2008; o delineamento experimental utilizado foi em blocos casualizados, em esquema fatorial $2 \times 6$, com quatro repetições. Os tratamentos se constituíram de duas cultivares de cebola, cultivar híbrida Optima F1 e cultivar não híbrida Alfa Tropical, além de seis tensões da água no solo, 15, 25, 35, 45, 60 e 75 kPa. Concluiu-se que o híbrido Optima $\mathrm{F} 1$ apresentou melhores respostas com relação às seguintes características analisadas: produtividade total de bulbos, produtividade de bulbos comerciais e massa média de bulbos comerciais. A altura da planta e o diâmetro do colo apresentaram respostas lineares decrescentes, sempre que se aumentaram as tensões da água no solo, para ambas as cultivares. Referidas cultivares devem ser irrigadas no momento em que a tensão da água no solo estiver em torno de $15 \mathrm{kPa}$, na profundidade de $0,15 \mathrm{~m}$, para obtenção de plantas mais altas, maiores produtividades de bulbos (total e comercial) e maior massa média de bulbos comerciais.
\end{abstract}

Palavras-chave: Allium cepa L., irrigação localizada, tensão da água no solo

\section{Development and production of two onion cultivars irrigated by drip system}

\begin{abstract}
This work aimed to assess the effect of different water tensions in soil over the development and production of two onion cultivars irrigated by drip system. The experiment was carried in the experimental area of the DAG/UFLA, from June to October 2008. The experimental was conducted in randomized block design in $2 \times 6$ factorial scheme, with four repetitions. The treatments were two onion cultivars, the hybrid Optima F1 and the non hybrid Alfa Tropical and six soil water tensions, i.e., 15, 25, 35, 45, 60 and 75 $\mathrm{kPa}$. It was verified that the hybrid Optima F1 presented the best responses regarding the following analyzed characteristics: total bulb yield, commercial bulb yield and average mass of commercial bulbs. The plant height and the hypocotyl diameter presented linear decreasing response as the soil water tensions were increased, for both cultivars. In both cultivars, in order to achieve taller plants, higher bulb yields (total and commercial) and higher average mass of commercial bulbs, the irrigation should be applied when the soil water tensions is around $15 \mathrm{kPa}$ at $0.15 \mathrm{~m}$ depth.
\end{abstract}

Key words: Allium cepa L., trickle irrigation, soil water tension

\footnotetext{
Extraído da Tese de Doutorado do primeiro autor, apresentada à Universidade Federal de Lavras (UFLA). Trabalho financiado pela FAPEMIG 2 Doutor em Engenharia Agrícola/Engenharia de Água e Solo, Rua João Renato de Pádua 65, CEP 37200-000, Lavras, MG. Fone (35) $3822-5079$. E-mail: renatovilasboas@yahoo.com.br

DEG/UFLA. Fone (35) 3829-1389. E-mail: geraldop@ufla.br

DAG/UFLA. Fone (35) 3829-1779. E-mail: rovilson@ufla.br

Doutorando do DEG/UFLA. Fone (35) 3829-1389. E-mail: lucianogeisenhoff@ig.com.br; joaquim.junior@ufra.edu.br
} 


\section{INTRODUÇÃO}

A cebola (Allium cepa) ocupa, entre as hortaliças cultivadas, a terceira posição em importância econômica no Brasil, ficando atrás apenas da batata e do tomate (Gonçalves et al., 2009). Em 2011 a produtividade média nacional, de acordo com o IBGE (2012), se manteve em torno de $23.278 \mathrm{~kg} \mathrm{ha}^{-1}$.

Tendo em vista sua sensibilidade ao déficit hídrico, muitos trabalhos sobre a irrigação da cultura da cebola evidenciam que a produtividade de bulbos é altamente dependente da quantidade de água aplicada (Santa-Olalla et al., 1994; AbuAwwad, 1996; Saha et al., 1997; Koriem et al., 1999; Shock et al., 2000). Entretanto, em poucos estudos são analisados critérios de manejo da irrigação por gotejamento nesta cultura (Chopade et al., 1998; Shock et al., 2000; Santa Olalla et al., 2004).

O manejo otimizado da irrigação requer uma estimativa sistemática do estado energético de água no solo, para determinar as quantidades apropriadas e o tempo de irrigação. Segundo Morgan et al. (2001), o teor de água do solo deve ser mantido entre certos limites específicos, cuja água disponível para a planta não seja limitada, enquanto a lixiviação é prevenida. Porém uma prática de manejo bastante utilizada em áreas que utilizam água de qualidade inferior, é a fração de lixiviação, por se tratar de uma quantidade extra de água, relativa à que é aplicada e penetra no solo, acarretando a lixiviação dos sais (Carvalho et al., 2012). Sabendo-se quando irrigar pela tensão da água no solo por meio do tensiômetro, estabelecese o quanto de água deve ser aplicado pela irrigação com base no armazenamento de água no solo.

Em trabalhos realizados por Guerra et al. (1994), Guerra (1995), Gondim et al. (2000), Santos \& Pereira (2004), Sá et al. (2005) e Lima Júnior et al. (2012) verifica-se ser a tensão da água no solo indicada não apenas para determinar o momento de irrigar mas também para estimar a quantidade de água a ser aplicada em várias culturas.

Com referência ao modo de aplicação de água, os sistemas por aspersão são os mais utilizados para a irrigação da cultura da cebola no Brasil, destacando-se o convencional, especialmente nas regiões Sul e Sudeste. Em grandes áreas o sistema pivô central é utilizado com sucesso (Costa et al., 2002). No entanto, em virtude da preocupação, em nível mundial, com a questão do gerenciamento, conservação e economia dos recursos hídricos tem-se recomendado, para a grande maioria das culturas, o uso do método de irrigação localizada (sistemas de microaspersão e gotejamento), por ser mais eficiente na aplicação de água e de fertilizantes (Nogueira et al., 1998).

No Brasil, estudos referentes à produção de cebola irrigada por gotejamento ainda são escassos. Desta forma, é grande a necessidade de desenvolvimento de pesquisas sobre o manejo adequado da irrigação por gotejamento na cultura da cebola com o intuito de dar suporte ao emprego dessa tecnologia de produção, visando determinar tanto o momento oportuno de irrigar quanto a quantidade de água a ser aplicada na cultura.
Com base no exposto objetivou-se, neste trabalho, avaliar o efeito de diferentes tensões da água no solo sobre o desenvolvimento e produção de duas cultivares de cebola irrigadas por gotejamento.

\section{MATERIAL E MÉTODOS}

O experimento foi conduzido no período de junho a outubro de 2008, em canteiros construídos a céu aberto, na área experimental do Departamento de Agricultura da Universidade Federal de Lavras (UFLA), Setor de Olericultura, no município de Lavras, sul de Minas Gerais, tendo como referência as seguintes coordenadas geográficas: latitude $21^{\circ} 14^{\prime} \mathrm{S}$, longitude $45^{\circ} 00^{\prime}$ W Gr. e $918,8 \mathrm{~m}$ de altitude.

De acordo com a classificação climática de Köppen (Dantas et al., 2007), o clima de Lavras é Cwa, ou seja, temperado chuvoso (mesotérmico), com inverno seco e verão chuvoso, subtropical. A temperatura média do mês mais frio é inferior a $18^{\circ} \mathrm{C}$ e superior a $3{ }^{\circ} \mathrm{C}$ e o verão apresenta temperatura média do mês mais quente superior a $22^{\circ} \mathrm{C}\left(22,1^{\circ} \mathrm{C}\right.$ em fevereiro). A temperatura do ar média anual de Lavras é de $19,4^{\circ} \mathrm{C}$, umidade relativa do ar média de $76,2 \%$, precipitação média anual de $1.529,7$ mm e evaporação média anual de 1.034,3 mm (Brasil, 1992).

O solo foi classificado como Latossolo Vermelho Distroférrico, textura muito argilosa, sendo a composição química na camada de 0-0,30 m, apresentada na Tabela 1 .

A curva de retenção da água no solo é representada pela Eq. 1, segundo o modelo de Genuchten (1980):

$$
\theta=0,231+\frac{0,381}{\left[1+(0,485 \cdot|\Psi|)^{1,734}\right]^{0,423}}
$$

em que:

$\theta \quad$ - umidade com base em volume, $\mathrm{cm}^{3} \mathrm{~cm}^{-3}$

$\Psi$ - tensão da água no solo, $\mathrm{kPa}$

Utilizou-se o delineamento em blocos casualizados (DBC) cujos tratamentos foram distribuídos em esquema fatorial $2 \times 6$, sendo utilizados 12 tratamentos, quatro repetições e 56 plantas por parcela. Os tratamentos se constituíram de duas cultivares de cebola de ciclo precoce, cultivar não híbrida Alfa Tropical (A) e cultivar híbrida Optima F1 (O) e seis tensões da água no solo, $15,25,35,45,60$ e $75 \mathrm{kPa}$ como indicativo do momento de irrigar (tensão crítica). Os tratamentos foram assim representados: A15, A25, A35, A45, A60, A75, O15, O25, O35, O45, O60 e O75.

Com relação às características dos materiais estudados a cultivar Alfa Tropical apresenta bulbos com coloração amarela, alta pungência e formato predominantemente globular alongado enquanto os bulbos do híbrido Optima F1 possuem coloração

Tabela 1. Composição química do solo utilizado no experimento

\begin{tabular}{|c|c|c|c|c|c|c|c|c|c|c|c|c|c|c|}
\hline \multirow{2}{*}{$\begin{array}{c}\mathrm{pH} \\
\mathrm{H}_{2} \mathrm{O}\end{array}$} & \multirow{2}{*}{$\begin{array}{c}\text { M.O. } \\
\text { dag } \text { kg }^{-1}\end{array}$} & $\mathbf{P}$ & K & $S$ & $\mathrm{Zn}$ & $\mathrm{Fe}$ & Mn & $\mathrm{Cu}$ & B & $\mathrm{Ca}^{2+}$ & $\mathrm{Mg}^{2+}$ & $\mathrm{Al}^{3+}$ & $\mathrm{H}+\mathrm{Al}$ & V \\
\hline & & \multicolumn{8}{|c|}{$\mathrm{mg} \mathrm{dm}^{-3}$} & \multicolumn{4}{|c|}{$\mathrm{cmol}_{\mathrm{c}} \mathrm{dm}^{-3}$} & $\%$ \\
\hline 5,6 & 3,0 & 4,3 & 119,0 & 22,7 & 9,8 & 40,1 & 16,4 & 3,0 & 0,9 & 1,8 & 0,4 & 0,2 & 4,0 & 38,5 \\
\hline
\end{tabular}


amarelo escuro, baixa pungência e formato globular (Oliveira et al., 2004).

Para monitorar o estado de energia da água no solo foi instalado um conjunto com três tensiômetros por parcela (dois a $0,15 \mathrm{~m}$ de profundidade para monitorar a irrigação e um a $0,30 \mathrm{~m}$ de profundidade para verificar a ocorrência de percolação) sendo que, para cada tratamento, os conjuntos de tensiômetros foram instalados em duas das quatro repetições. Os tensiômetros foram instalados no alinhamento da cultura entre duas plantas e ficaram 0,20 m distanciados entre si, em cada conjunto.

As parcelas experimentais tiveram dimensões de 1,20 m de largura por 1,40 m de comprimento. Foram utilizadas quatro linhas de plantas espaçadas $0,20 \mathrm{~m}$ entre si e $0,10 \mathrm{~m}$ entre plantas. Foram consideradas úteis as plantas das linhas centrais e descartadas, nessas linhas, duas plantas no início e duas no final (parcela útil com 20 plantas).

As mudas foram obtidas por semeadura em bandejas de poliestireno expandido com 200 células, utilizando-se o substrato comercial Plantmax ${ }^{\circledR}$ HT. Após o transplante das mudas, aos 40 dias após a semeadura, a irrigação foi realizada por microaspersão com o tape SANTENO ${ }^{\circledR}$. Este sistema foi usado até 14 dias após o transplante (DAT), período este necessário para o pegamento e a aclimatização das mudas, no campo. Na diferenciação dos tratamentos utilizou-se um sistema de irrigação por gotejamento sendo os emissores autocompensantes do tipo in-line, modelo NAAN PC com vazão nominal de $1,6 \mathrm{~L} \mathrm{~h}^{-1}$ distanciados entre si a $0,30 \mathrm{~m}$. O tubogotejador ficou posicionado na parcela de forma a atender às duas fileiras de plantas, trabalhando com pressão de serviço de $140 \mathrm{kPa}$, após o que se suspendeu a irrigação da cultura, sete dias antes de cada colheita.

Buscava-se, em todas as irrigações, elevar à capacidade de campo a umidade correspondente à tensão verificada no momento de irrigar. O instante de irrigar foi estabelecido como aquele em que pelo menos três dos tensiômetros de decisão (instalados a $0,15 \mathrm{~m}$ de profundidade) atingiam a tensão crítica estabelecida para cada tratamento. Calculou-se o tempo de funcionamento do sistema de irrigação a partir da lâmina bruta, considerando-se a profundidade efetiva do sistema radicular igual a $0,30 \mathrm{~m}$. A eficiência de aplicação de água do sistema de irrigação foi adotada como $90 \%$.

Como adubação de plantio foram aplicados $90 \mathrm{~kg} \mathrm{ha}^{-1} \mathrm{de}$ uréia, $1.500 \mathrm{~kg} \mathrm{ha}^{-1}$ de superfosfato simples, $35 \mathrm{~kg} \mathrm{ha}^{-1}$ de cloreto de potássio, $15 \mathrm{~kg} \mathrm{ha}^{-1}$ de sulfato de zinco e $10 \mathrm{~kg} \mathrm{ha}^{-1}$ de bórax, com base nas análises de solo e conforme as recomendações de Fontes (1999). Já a adubação de cobertura foi realizada manualmente, aos 30 e 45 DAT, sendo aplicados, em cada cobertura, $100 \mathrm{~kg} \mathrm{ha}^{-1}$ de sulfato de amônio e $65 \mathrm{~kg} \mathrm{ha}^{-1}$ de cloreto de potássio, de acordo com as recomendações de Ferreira (2000).

Avaliou-se o desenvolvimento vegetativo da cultura aos 100 DAT realizando-se a medida, em seis plantas, da parcela útil, tomadas aleatoriamente, com vista à determinação da altura da planta e do diâmetro na região do colo.

As colheitas foram realizadas quando mais de $60 \%$ das plantas se encontravam estaladas (Vidigal et al., 2010), isto é, com o pseudocaule completamente prostrado sobre o solo, aos 111 DAT (híbrido Optima F1) e aos 118 DAT (cultivar Alfa Tropical). As plantas foram arrancadas manualmente e mantidas ao sol durante três dias; em seguida, 12 dias à sombra em galpão ventilado, para o período de cura.

Decorrido o período de cura fez-se a toalete procedendose, a seguir, à avaliação das seguintes características de produção: produtividade total de bulbos, produtividade de bulbos comerciais e massa média de bulbos comerciais, em que os dados obtidos foram submetidos à análise de variância com a realização do teste $\mathrm{F}$, comparação de médias pelo teste de Tukey e análise de regressão polinomial a 5 e $1 \%$ de probabilidade.

\section{RESULTADOS E DISCUSSÃO}

No período de condução do experimento a temperatura diária média do ar foi de $18,4^{\circ} \mathrm{C}$. O valor médio diário de temperatura encontrado neste estudo, está de acordo com Souza \& Resende (2002), ao relatarem que as temperaturas críticas de interferência no desenvolvimento da cultura da cebola se situam abaixo de $10^{\circ} \mathrm{C}$ e acima de $32^{\circ} \mathrm{C}$.

As lâminas de água aplicadas antes (INIC) e após a diferenciação dos tratamentos (IRRIG), tal como as precipitações ocorridas (Precipitação), os totais de água fornecidos, para a cultura (Totais), a média por irrigação (MPI), o turno de rega (TR) e o número de irrigações (NI) computados durante a diferenciação dos tratamentos, são apresentados na Tabela 2.

Tabela 2. Tensões da água no solo na profundidade de $0,15 \mathrm{~m}$, lâminas aplicadas antes da diferenciação dos tratamentos (INIC), lâminas aplicadas após a diferenciação dos tratamentos (IRRIG), precipitações ocorridas (Precipitação), lâminas totais de água (Totais), média por irrigação (MPI), turno de rega (TR) e número de irrigações (NI)

\begin{tabular}{|c|c|c|c|c|c|c|c|c|}
\hline \multirow{2}{*}{ Tratamento } & \multirow{2}{*}{$\begin{array}{c}\text { Tensão } \\
\text { (kPa) }\end{array}$} & \multicolumn{5}{|c|}{ Lâmina (mm) } & \multirow{2}{*}{$\begin{array}{c}\text { TR } \\
\text { (dia) }\end{array}$} & \multirow{2}{*}{$\begin{array}{c}\mathrm{NI} \\
\text { (ud) }\end{array}$} \\
\hline & & INIC & IRRIG & Precipitação & Totais & MPI & & \\
\hline A15 & 15 & 41,4 & 464,5 & 109,3 & 615,2 & 10,8 & 2,7 & 43 \\
\hline A25 & 25 & 41,4 & 423,4 & 109,3 & 574,1 & 20,2 & 5,6 & 21 \\
\hline A35 & 35 & 41,4 & 392,7 & 109,3 & 543,4 & 24,5 & 7,4 & 16 \\
\hline A45 & 45 & 41,4 & 355,5 & 109,3 & 506,2 & 27,3 & 9,1 & 13 \\
\hline A60 & 60 & 41,4 & 240,2 & 109,3 & 390,9 & 30,0 & 14,8 & 8 \\
\hline A75 & 75 & 41,4 & 126,2 & 109,3 & 276,9 & 31,5 & 29,5 & 4 \\
\hline 015 & 15 & 41,4 & 452,9 & 109,3 & 603,6 & 10,5 & 2,6 & 43 \\
\hline 025 & 25 & 41,4 & 363,4 & 109,3 & 514,1 & 20,2 & 6,2 & 18 \\
\hline 035 & 35 & 41,4 & 296,5 & 109,3 & 447,2 & 24,7 & 9,3 & 12 \\
\hline 045 & 45 & 41,4 & 248,2 & 109,3 & 398,9 & 27,6 & 12,3 & 9 \\
\hline 060 & 60 & 41,4 & 209,4 & 109,3 & 360,1 & 29,9 & 15,9 & 7 \\
\hline 075 & 75 & 41,4 & 94,7 & 109,3 & 245,4 & 31,6 & 37,0 & 3 \\
\hline
\end{tabular}


Observou-se que as lâminas totais de água aplicadas seguiram um padrão decrescente em relação às tensões da água no solo estabelecidas para ambas as cultivares, isto é, as maiores lâminas foram observadas nos tratamentos com menores tensões, comportando-se de maneira análoga a Marouelli et al. (2003).

Verificam-se, de acordo com a análise de variância (Tabela 3 ), diferenças significativas a $1 \%$ de probabilidade para a altura da planta com relação ao fator tensões da água no solo e, para o diâmetro do colo, com referência aos fatores cultivares e tensões da água no solo; no entanto, a interação entre os fatores não apresentou diferença significativa para essas características estudadas.

Tabela 3. Resumo das análises de variância e de regressão para altura da planta (AP) e diâmetro do colo (DC) de duas cultivares de cebola sob diferentes tensões da água no solo

\begin{tabular}{|c|c|c|c|}
\hline \multirow{2}{*}{ Fontes de variação } & \multirow{2}{*}{ G.L. } & \multicolumn{2}{|c|}{ Quadrado médio (cm) } \\
\hline & & AP & DC \\
\hline Bloco & 3 & $29,47^{\text {ns }}$ & $0,05^{\text {ns }}$ \\
\hline Cultivar & 1 & $25,81^{\text {ns }}$ & $1,13^{\text {** }}$ \\
\hline Tensão & 5 & $137,58^{* *}$ & 0,36 ** \\
\hline Cultivar x Tensão & 5 & $6,75^{\mathrm{ns}}$ & $0,03^{\text {ns }}$ \\
\hline Resíduo & 33 & 13,60 & 0,02 \\
\hline Média Geral & - & 54,14 & 1,85 \\
\hline C.V. (\%) & - & 6,81 & 7,50 \\
\hline Tensões & 5 & $137,58^{* *}$ & $0,36^{* *}$ \\
\hline Linear & 1 & $641,35^{\text {** }}$ & $1,77^{\text {**}}$ \\
\hline Quadrática & 1 & $9,31^{\mathrm{ns}}$ & 0,00 ns \\
\hline Desvios & 3 & $12,42^{\text {ns }}$ & $0,02^{\text {ns }}$ \\
\hline
\end{tabular}

ns - não significativo pelo teste $\mathrm{F}$

** - significativo a $1 \%$ de probabilidade pelo teste $F$

A altura da planta foi influenciada pelas tensões da água no solo evidenciando resposta linear com nível de significância de $1 \%$ (Tabela 3), sinalizando um decréscimo da altura da planta à medida em que se aumentaram as tensões da água no solo. Notase que $93,21 \%$ das variações ocorridas na altura da planta em função das tensões, são explicados pela regressão linear (Figura 1A). O valor máximo para a altura da planta ocorreu na tensão de $15 \mathrm{kPa}$ resultando na altura de $59,1 \mathrm{~cm}$, para esta característica.

De posse dos resultados encontrados neste estudo percebese que a umidade do solo favoreceu, de forma direta, a taxa de crescimento das plantas de cebola, ao evidenciar que irrigações mais frequentes mantendo a umidade do solo próxima à capacidade de campo, contribuíram para a obtenção de plantas mais altas.

Segundo Taiz \& Zeiger (2004), a redução da área foliar pode ser considerada a primeira linha de defesa das plantas contra o déficit hídrico. Com a diminuição do conteúdo de água da planta ocorre diminuição do turgor das células provocando lentidão na expansão foliar. Além disso, quanto menor a quantidade de água disponível no solo para as plantas maior será a diminuição do crescimento pois, de acordo com Rego et al. (2004), o déficit hídrico provoca o fechamento dos estômatos diminuindo a assimilação de $\mathrm{CO}_{2}$ e, em contrapartida, as atividades fisiológicas das plantas, principalmente a divisão e o crescimento das células.
A.

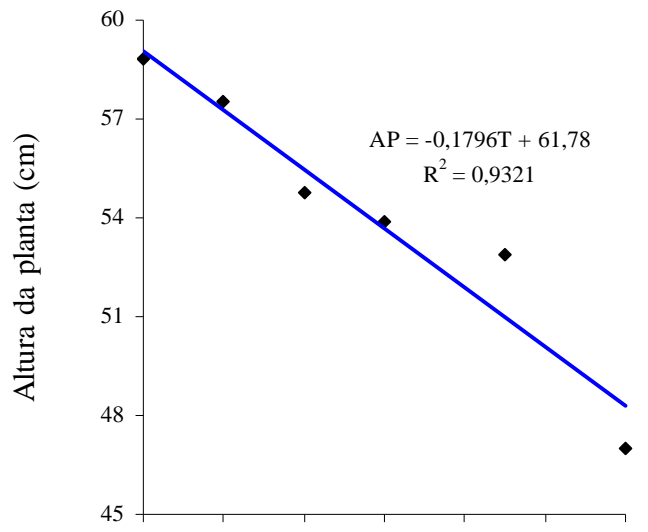

B.

C.
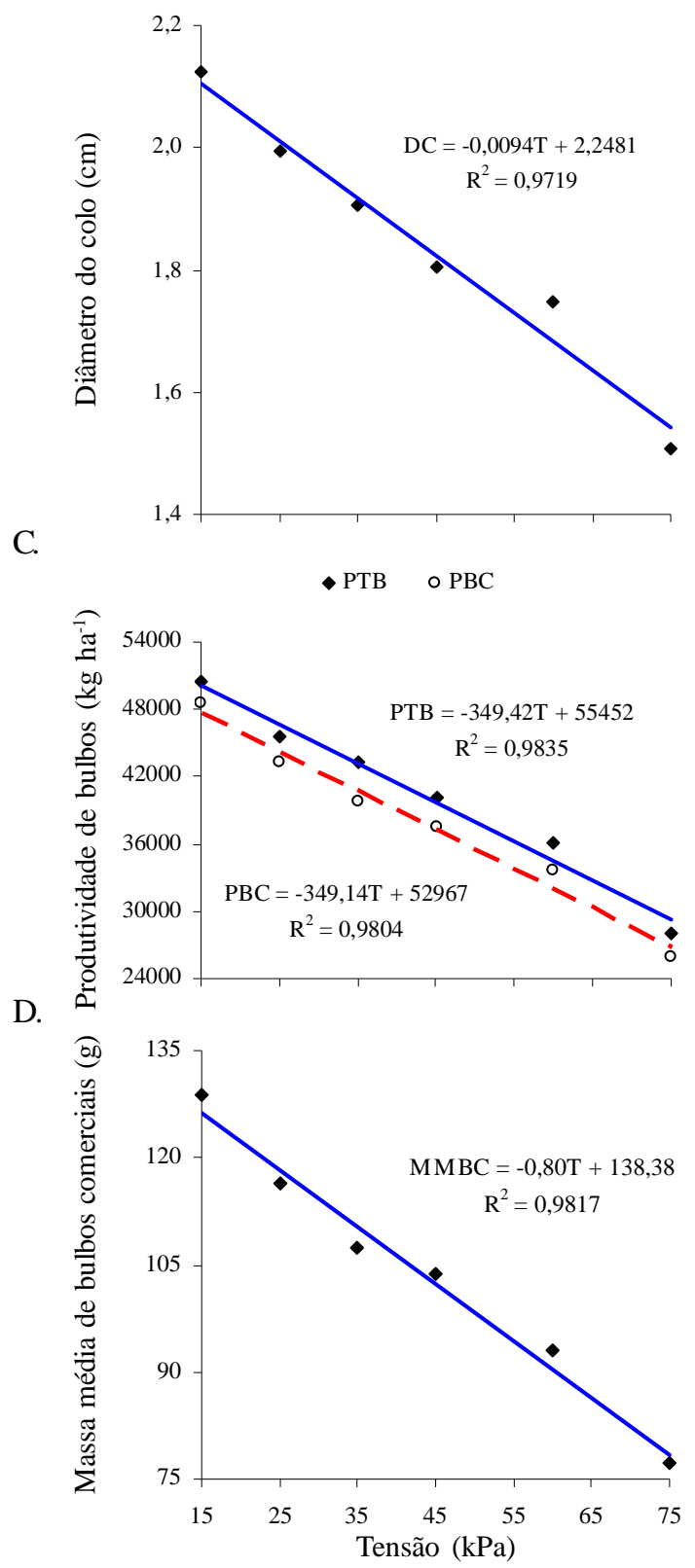

Figura 1. Altura da planta (AP) (A), diâmetro do colo (DC) (B), produtividade total de bulbos (PTB) e produtividade de bulbos comerciais (PBC) (C) e massa média de bulbos comerciais (MMBC) (D) de cebola, em função das diferentes tensões da água no solo 
Segundo o teste de médias (Tabela 4), o maior diâmetro do colo da planta de cebola foi obtido pela cultivar Alfa Tropical $(2,0 \mathrm{~cm})$, quando comparado ao do híbrido Optima F1 $(1,7 \mathrm{~cm})$, mostrando que a cultivar se apresentou com diâmetro de $17,7 \%$ maior, diferença que pode estar ligada a fatores genéticos de cada material estudado.

Tabela 4. Diâmetro do colo (DC), produtividade total de bulbos (PTB), produtividade de bulbos comerciais (PBC) e massa média de bulbos comerciais (MMBC) de duas cultivares de cebola sob diferentes tensões da água no solo

\begin{tabular}{|c|c|c|c|c|}
\hline \multirow{2}{*}{ Cultivar } & \multirow{2}{*}{$\begin{array}{l}\mathrm{DC}^{1} \\
(\mathrm{~cm})\end{array}$} & PTB & PBC & \multirow{2}{*}{$\begin{array}{c}\text { MMBC } \\
\text { (g) }\end{array}$} \\
\hline & & \multicolumn{2}{|c|}{$\left(\mathrm{kg} \mathrm{ha}^{-1}\right)$} & \\
\hline Optima F1 & $1,7 b$ & $45.005,6 \mathrm{a}$ & $42.780,5 \mathrm{a}$ & $114,2 \mathrm{a}$ \\
\hline Alfa Tropical & $2,0 \mathrm{a}$ & $36.198,3 \mathrm{~b}$ & $33.477,3 \mathrm{~b}$ & $94,7 \mathrm{~b}$ \\
\hline Desvio padrão & 0,1 & $4.385,0$ & $4.804,2$ & 12,4 \\
\hline
\end{tabular}

${ }^{1}$ Médias seguidas de letras diferentes na vertical diferem estatisticamente entre si, pelo teste de Tukey, a $5 \%$ de probabilidade

No caso do diâmetro do colo, as variações ocorridas podem ser explicadas pela regressão linear, a $1 \%$ de probabilidade (Tabela 3). O valor médio encontrado para o diâmetro do colo foi de $1,85 \mathrm{~cm}$. De acordo com a equação apresentada na Figura $1 \mathrm{~B}$, o aumento de uma unidade na tensão da água no solo $(\mathrm{kPa})$ reduz em $0,0094 \mathrm{~cm}$ o diâmetro do colo das plantas de cebola. Observa-se que $97,19 \%$ das variações ocorridas no diâmetro do colo em função das tensões, são explicados pela regressão linear; já o valor máximo obtido para o diâmetro do colo ocorreu na tensão de $15 \mathrm{kPa}$, resultando em um diâmetro de $2,1 \mathrm{~cm}$.

O fato das plantas de cebola apresentarem diâmetros do colo menores em níveis mais elevados de tensão da água no solo está relacionado, provavelmente, aos efeitos do estresse hídrico no crescimento das plantas. Esse estresse hídrico, segundo Davies \& Zhang (1991), pode provocar mudanças nas relações hídricas nas folhas que, por sua vez, afetam os processos químicos e fisiológicos e, em consequência, o crescimento e o desenvolvimento da parte aérea da planta.

De conformidade com a análise de variância (Tabela 5), verificam-se efeitos significativos a $1 \%$ de probabilidade para a produtividade total de bulbos, produtividade de bulbos comerciais e massa média de bulbos comerciais com relação aos fatores cultivares e tensões da água no solo; já a interação entre os fatores apresentou diferença significativa a $5 \%$ de probabilidade, para essas características estudadas.

Constata-se, pelo teste de médias (Tabela 4), maior produtividade total de bulbos para o híbrido Optima F1 (45.005,6 $\mathrm{kg} \mathrm{ha}^{-1}$ ), quando comparado com a cultivar Alfa Tropical $\left(36.198,3 \mathrm{~kg} \mathrm{ha}^{-1}\right)$, levando a crer que esta diferença seja devida apenas ao fator genético. Segundo Maluf (2001), os híbridos podem apresentar vantagens em relação às cultivares não híbridas, dentre elas a heterose (maior produtividade).

As produtividades totais médias de bulbos obtidas neste trabalho, de 45.005,6 $\mathrm{kg} \mathrm{ha}^{-1}$ para o híbrido Optima F1 e de 36.198,3 $\mathrm{kg} \mathrm{ha}^{-1}$ para a cultivar Alfa Tropical, foram superiores à média brasileira que, segundo IBGE (2012), é de $23.278 \mathrm{~kg} \mathrm{ha}^{-1}$.

$\mathrm{O}$ resultado de produtividade total de bulbos mostrou resposta linear com nível de significância de 1\% (Tabela 5), indicando haver um decréscimo da produtividade total de
Tabela 5. Resumo das análises de variância e de regressão para produtividade total de bulbos (PTB), produtividade de bulbos comerciais (PBC) e massa média de bulbos comerciais $(\mathrm{MMBC})$ de duas cultivares de cebola sob diferentes tensões da água no solo

\begin{tabular}{|c|c|c|c|c|}
\hline \multirow{3}{*}{$\begin{array}{l}\text { Fontes de } \\
\text { variação }\end{array}$} & \multirow{3}{*}{ G.L. } & \multicolumn{3}{|c|}{ Q. M. } \\
\hline & & РТВ & PBC & \multirow{2}{*}{$\begin{array}{c}\text { MMBC } \\
(\mathbf{g})\end{array}$} \\
\hline & & \multicolumn{2}{|c|}{$\left(\mathrm{kg} \mathrm{ha}^{-1}\right)$} & \\
\hline Bloco & 3 & $35833947,6^{\mathrm{ns}}$ & is $\quad 71459247,1^{*}$ & $76,0^{\text {ns }}$ \\
\hline Cultivar & 1 & 930820638,0 ** & 1038605520,0 ** & $4537,7^{\text {** }}$ \\
\hline Tensão & 5 & $494098736,5^{* *}$ & $494847275,8^{* *}$ & $2586,6^{* *}$ \\
\hline Cultivar x Tensão & 5 & $59236390,5^{*}$ & $69266283,3^{*}$ & $401,5^{*}$ \\
\hline Resíduo & 33 & 19064121,2 & 22999084,4 & 154,6 \\
\hline Média Geral & - & 40602,0 & 38128,9 & 104,5 \\
\hline C.V. (\%) & - & 10,8 & 12,6 & 11,9 \\
\hline Tensão & 5 & $494098736,5^{\star \star}$ & $494847275,8^{* *}$ & $2586,6^{* *}$ \\
\hline Linear & 1 & $2429694416,0^{* *}$ & * $2425749305,9^{* *}$ & 12695,6 ** \\
\hline Quadrática & 1 & $6816299,5^{\mathrm{ns}}$ & s $\quad 13738,4^{\text {ns }}$ & $2,4^{\mathrm{ns}}$ \\
\hline Desvios & 3 & $11327655,7^{\text {ns }}$ & $16157778,3^{\mathrm{ns}}$ & $78,3^{\mathrm{ns}}$ \\
\hline Tensões: Alfa Tropical & (5) & $123817946,7^{\text {** }}$ & $120779136,5^{* *}$ & $487,6^{*}$ \\
\hline Linear & 1 & $583244321,6^{* *}$ & $566127459,8^{* *}$ & $2422,4^{* *}$ \\
\hline Quadrática & 1 & $33872383,6^{\mathrm{ns}}$ & $20965357,6^{\text {ns }}$ & $0,3^{\mathrm{ns}}$ \\
\hline Desvios & 3 & $657676,0^{\text {ns }}$ & $5600955,1^{\text {ns }}$ & $5,1^{\mathrm{ns}}$ \\
\hline Tensões: Optima F1 & (5) & $429517180,4^{\star \star}$ & $443334422,5^{* *}$ & $2500,5^{\star *}$ \\
\hline Linear & 1 & $2075610170,1^{\text {** }}$ & $2103072354,8^{* *}$ & $12128,2^{* *}$ \\
\hline Quadrática & 1 & $4527378,1^{\mathrm{ns}}$ & is $\quad 19474858,9^{\text {ns }}$ & $7,5^{\mathrm{ns}}$ \\
\hline Desvios & 3 & $22482784,6^{\text {ns }}$ & $31374966,4^{\mathrm{ns}}$ & $122,2^{\mathrm{ns}}$ \\
\hline
\end{tabular}

bulbos sempre que se aumentaram as tensões da água no solo (Figura 1C). O valor máximo para a produtividade total de bulbos ocorreu na tensão de $15 \mathrm{kPa}$ resultando em uma produtividade de $50.211 \mathrm{~kg} \mathrm{ha}^{-1}$ para esta característica.

Analisando critérios de manejo da irrigação por gotejamento na cultura da cebola, Chopade et al. (1998) e Santa Olalla et al. (2004), também obtiveram melhores produtividades de bulbo quando o solo foi mantido constantemente com alto teor de água; comportamento semelhante encontraram Shock et al. (2000) que, em estudo sobre o manejo da irrigação por gotejamento na cultura da cebola, avaliaram cinco tensões da água no solo $(10,20,30,50$ e $70 \mathrm{kPa})$, medidas a $0,20 \mathrm{~m}$ de profundidade no ano de 1998 e concluíram que a produtividade total de bulbos apresentou resposta linear decrescente com o aumento da tensão alcançando o valor máximo de $59.670 \mathrm{~kg} \mathrm{ha}^{-1}$, com a tensão de $10 \mathrm{kPa}$.

Analisando a interação entre os fatores (cultivares versus tensões da água no solo) (Figura 2A) observa-se que, independente das cultivares estudadas, os melhores resultados de produtividade total de bulbos foram obtidos quando se reiniciavam as irrigações com a tensão de $15 \mathrm{kPa}$; apesar disto, percebe-se que o coeficiente angular da equação de regressão é menor para o híbrido Optima F1 $(-456,7)$, quando comparado com o da cultivar Alfa Tropical $(-242,1)$, isto é, o híbrido é mais responsivo à irrigação.

De acordo com o teste de médias (Tabela 4), a maior produtividade média de bulbos comerciais foi obtida pelo híbrido Optima F1 (42.780,5 kg ha-1) o qual apresentou incremento médio na produtividade comercial da ordem de 27,8\% acima, portanto, da cultivar Alfa Tropical. 
A.

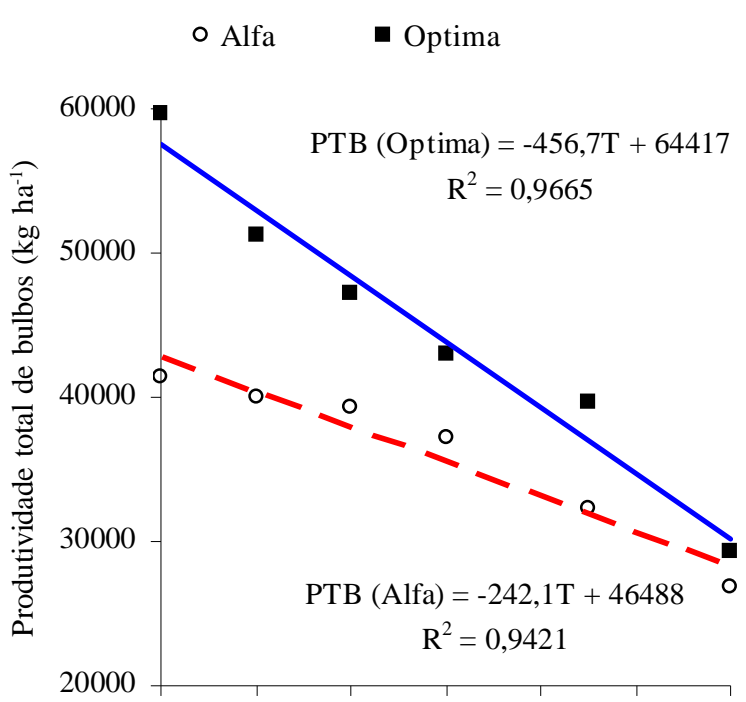

B.

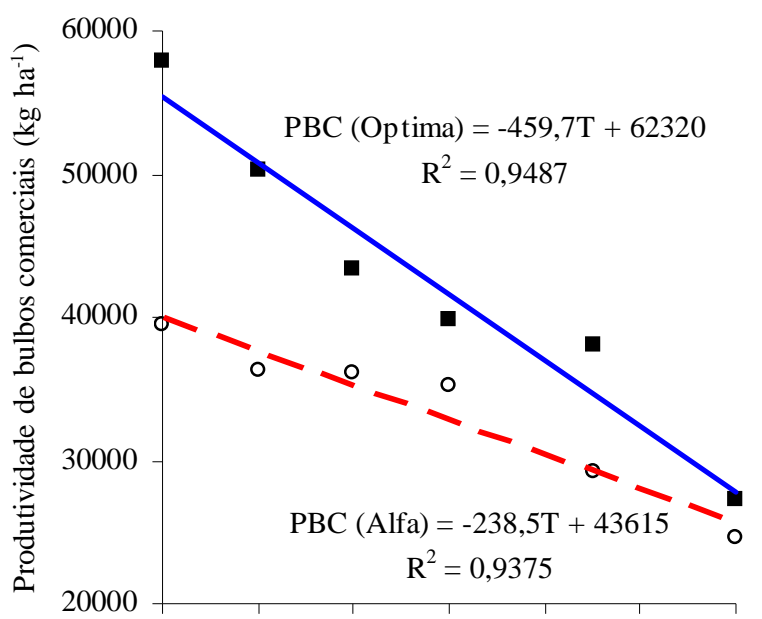

C.

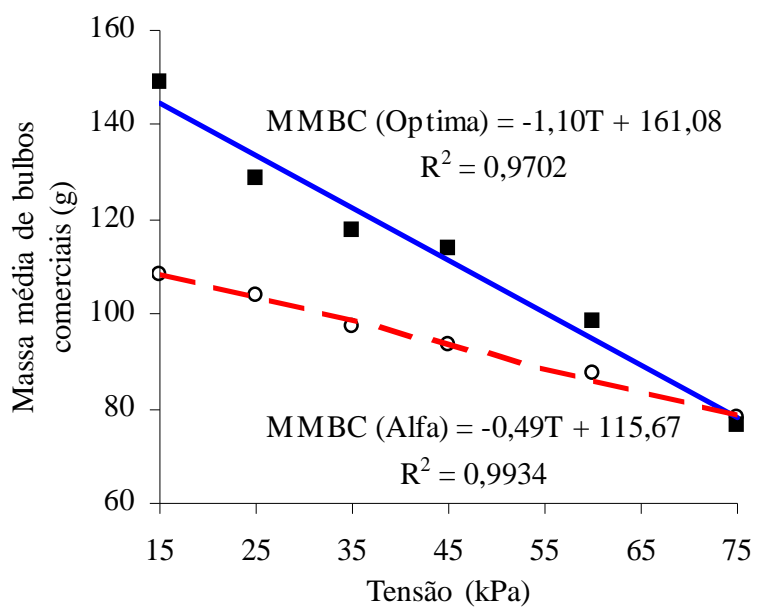

Figura 2. Produtividade total de bulbos (PTB) (A), produtividade de bulbos comerciais (PBC) (B) e massa média de bulbos comerciais (MMBC) (C) de duas cultivares de cebola em função das diferentes tensões da água no solo
Rebouças et al. (2008) também encontraram, em estudo sobre a densidade de plantio de cebola no sistema de semeadura, em Salinas, MG, para o híbrido Mercedes, produtividade comercial significativamente superior à da cultivar Serrana, registrando um incremento médio de $55,2 \%$ na produtividade de bulbos comerciais.

No caso da produtividade de bulbos comerciais, as variações ocorridas em função das tensões da água no solo podem ser explicadas pela regressão linear significativa a $1 \%$ de probabilidade (Tabela 5). De acordo com a equação apresentada na Figura $1 \mathrm{C}$, o aumento de uma unidade $(\mathrm{kPa})$ na tensão da água no solo reduz em aproximadamente $349,14 \mathrm{~kg} \mathrm{ha}^{-1}$ a produtividade de bulbos comerciais. $\mathrm{O}$ valor máximo encontrado para a produtividade de bulbos comerciais ocorreu na tensão de 15 $\mathrm{kPa}$ resultando em uma produtividade para este parâmetro, de $47.730 \mathrm{~kg} \mathrm{ha}^{-1}$.

Comportamento semelhante obtiveram Shock et al. (2000) que, visando definir critérios para o manejo da irrigação por gotejamento na cultura da cebola, avaliaram cinco tensões da água no solo $(10,20,30,50$ e $70 \mathrm{kPa})$, medidas a $0,20 \mathrm{~m}$ de profundidade e constataram que a produtividade de bulbos comerciais apresentou resposta linear decrescente com o aumento da tensão, alcançando o valor máximo de 56.310 $\mathrm{kg} \mathrm{ha}^{-1}$ com a tensão de $10 \mathrm{kPa}$.

$\mathrm{Na}$ interação entre os fatores estudados (cultivares versus tensões da água no solo) (Figura 2B), verifica-se comportamento semelhante ao encontrado para a produtividade total de bulbos, isto é, os melhores resultados de produtividade de bulbos comerciais, em ambas as cultivares, foram observados quando a irrigação foi reiniciada com a tensão de $15 \mathrm{kPa}$. O híbrido Optima F1 apresenta maior taxa de redução da produtividade de bulbos comerciais quando submetido a maiores tensões.

Observa-se, pelo teste de médias (Tabela 4), que o híbrido Optima F1 indicou maior massa média de bulbos comerciais (114,2 g), representando 20,6\% de massa a mais do que a cultivar Alfa Tropical (94,7 g). Rebouças et al. (2008) também obtiveram, para o híbrido Mercedes, um incremento na massa média de bulbos comerciais da ordem de 18,8\% em relação à cultivar Serrana.

O resultado de massa média de bulbos comerciais evidenciou resposta linear com nível de significância de $1 \%$ (Tabela 5), sinalizando um decréscimo da massa média de bulbos comerciais sempre que se aumentaram as tensões da água no solo (Figura 1D). O valor máximo de massa média de bulbos comerciais foi constatado na tensão de $15 \mathrm{kPa}$ resultando em uma massa média para esta característica, de 126,4 g.

Kumar et al. (2007) também constataram que a massa média de bulbos foi influenciada positivamente pelas lâminas de irrigação aplicadas e obtiveram valores de massa média de bulbos de 51,1 e 52,1 g, no tratamento submetido ao maior nível de irrigação (467,8 e 451,3 mm).

Em análise à interação entre os fatores cultivares versus tensões da água no solo (Figura 2C), conclui-se que a massa média de bulbos comerciais se relacionou de maneira inversa com a tensão da água no solo e diretamente com as lâminas de irrigação aplicadas (Tabela 2), independente das cultivares analisadas quando então os máximos valores foram obtidos na tensão de $15 \mathrm{kPa}$; já na tensão de $75 \mathrm{kPa}$ a massa média de bulbos comerciais foi praticamente igual entre as duas cultivares 
estudadas mostrando que o híbrido Optima F1 possui maior sensibilidade à variação da umidade do solo.

\section{CONClusÕES}

1. O híbrido Optima F1 apresentou melhores respostas com relação à produtividade total de bulbos, produtividade de bulbos comerciais e massa média de bulbos comerciais.

2. A altura da planta e o diâmetro do colo apresentaram respostas lineares decrescentes sempre que se aumentaram as tensões da água no solo, para ambas as cultivares.

3. Considerando o intervalo estudado ( 15 a $75 \mathrm{kPa})$ em ambas as cultivares, deve-se irrigar no momento em que a tensão da água no solo estiver em torno de $15 \mathrm{kPa}$, na profundidade de $0,15 \mathrm{~m}$, visando à obtenção de plantas mais altas, maiores produtividades de bulbo (total e comercial) e maior massa média de bulbos comerciais.

\section{Agradecimentos}

À FAPEMIG - Fundação de Amparo à Pesquisa do Estado de Minas Gerais, pelo financiamento do projeto de pesquisa (Processo: CAG-APQ-1569-3.12/07) e pela concessão da bolsa de Doutorado; ao CNPq - Conselho Nacional de Desenvolvimento Científico e Tecnológico, pela concessão da bolsa de Produtividade em Pesquisa.

\section{LITERATURA CITADA}

Abu-Awwad, A. M. Irrigation water management for onion trickle irrigated with saline drainage water. Pure and Applied Sciences, v.23, p.46-54, 1996.

Brasil. Ministério da Agricultura e da Reforma Agrária. Departamento Nacional de Meteorologia. Normais climatológicas: 1961-1990. Brasília: Embrapa/SPI, 1992. 84p.

Carvalho, J. F.; Tsimpho, C. J.; Silva, E. F. F.; Medeiros, P. R. F.; Santos, M. H. V.; Santos, A. N. Produção e biometria do milho verde irrigado com água salina sob frações de lixiviação. Revista Brasileira de Engenharia Agrícola e Ambiental, v.16, p.368-374, 2012.

Chopade, S. O.; Bansode, P. N.; Hiwase, S. S. Studies on fertilizer and water management to onion. PKV Research Journal, v.22, p.44-47, 1998.

Costa, E. L.; Marouelli, W. A.; Camboim Neto, L. F.; Silva, W. L. C. Irrigação da cebola. Informe Agropecuário, v.23, p.57-66, 2002.

Dantas, A. A. A.; Carvalho, L. G.; Ferreira, E. Classificação e tendências climáticas em Lavras, MG. Ciência e Agrotecnologia, v.31, p.1862-1866, 2007.

Davies, W. J.; Zhang, J. Root signal and regulation of growth and development of plants in drying soil. Annual Review Plant Physiology, v.42, p.55-76, 1991.

Ferreira, M. D. Cultura da cebola: Recomendações técnicas. Campinas: ASGROW, 2000.36p.
Fontes, P. C. R. Cebola. In: Ribeiro, A. C.; Guimarães, P. T. G.; Alvarez V., V. H. (ed.). Recomendação para o uso de corretivos e fertilizantes em Minas Gerais: $5^{\mathrm{a}}$ aproximação. Viçosa: CFSEMG, 1999. 184p.

Genuchten, M. A closed-form equation for predicting the hydraulic conductivity of unsaturated soils. Soil Science Society American Journal, v.44, p.892-898, 1980.

Gonçalves, P. A. S.; Wordell Filho, J. A.; Kurtz, C. Efeitos da adubação sobre a incidência de tripes e míldio e na produtividade da cultura da cebola. Revista Agropecuária Catarinense, v.22, p.57-60, 2009.

Gondim, R. S.; Aguiar, J. V.; Costa, R. N. T. Estratégias de manejo de água em caupi irrigado. Revista Brasileira de Engenharia Agrícola e Ambiental, v.4, p.14-18, 2000.

Guerra, A. F. Tensão de água no solo: efeito sobre a produtividade e qualidade dos grãos de cevada. Pesquisa Agropecuária Brasileira, v.30, p.245-254, 1995.

Guerra, A. F.; Silva, E. M.; Azevedo, J. A. Tensão de água no solo: um critério viável para a irrigação do trigo na região do cerrado. Pesquisa Agropecuária Brasileira, v.29, p.631-636, 1994.

IBGE - Instituto Brasileiro de Geografia e Estatística. Levantamento sistemático da produção agrícola. Rio de Janeiro, v.25, p.1-88, 2012.

Koriem, S. O.; El-Koliey, M. M.; El-Sheekh, H. M. Effect of drought conditions on yield, quality and some water relationships of onion. Journal of Agricultural Sciences, v.30, p.75-84, 1999.

Kumar, S.; Imtiyaz, M.; Kumar, A.; Singh, R. Response of onion (Allium cepa L.) to different levels of irrigation water. Agricultural Water Management, v.89, p.161-166, 2007.

Lima Júnior, J. A.; Pereira, G. M.; Geisenhoff, L. O.; Silva, W. G.; Vilas Boas, R. C.; Souza, R. J. Desempenho de cultivares de cenoura em função da água no solo. Revista Brasileira de Engenharia Agrícola e Ambiental, v.16, p.514-520, 2012.

Maluf, W. R. Produção de hortaliças I. Lavras: UFLA, 2001. $70 \mathrm{p}$.

Marouelli, W. A.; Silva, W. L. C.; Moretti, C. L. Resposta do tomateiro para processamento a tensões de água no solo, sob irrigação por gotejamento. Engenharia Agrícola, v.23, p.1-8, 2003.

Morgan, K. T.; Parsons, L. R.; Wheaton, T. A. Comparison of laboratory and field, derived soil water retention curves for a fine sand soil using tensiometric resistance and capacitance methods. Plant and Soil, v.234, p.153-157, 2001.

Nogueira, L. C.; Nogueira, L. R. Q.; Miranda, F. R. Irrigação do coqueiro. In: Ferreira, J. M. S.; Warwick, D. R. N.; Siqueira, L. A. (ed.). A cultura do coqueiro no Brasil. 2.ed. rev. e ampl. Brasília: Embrapa/SPI; Aracaju: Embrapa/CPATC, 1998. p.159-187.

Oliveira, V. R.; Leite, D. L.; Santos, C. A. F.; Costa, N. D.; Melo, P. C. T. Sistema de produção de cebola (Allium cepa L.): Cultivares. Brasília: Embrapa/CNPH, 2004. Sistemas de Produção n.5.

Rebouças, T. N. H.; Siqueira, L. G.; Lemos, O. L.; Grisi, F. A. Densidade de plantio em cebola no sistema de semeadura no Norte de Minas Gerais. Magistra, v.20, p.78-86, 2008. 
Rego, J. L.; Viana, T. V. A.; Azevedo, B. M.; Bastos, F. G. C. Efeitos de níveis de irrigação sobre a cultura do crisântemo. Revista Ciência Agronômica, v.35, p.302-308, 2004.

Sá, N. S. A.; Pereira, G. M.; Alvarenga, M. A. R.; Mattioli, W.; Carvalho, J. A. Comportamento da cultura do tomateiro sob diferentes tensões de água no solo em ambiente protegido. Revista Brasileira de Engenharia Agrícola e Ambiental, v.9, p.341-347, 2005.

Saha, U. K.; Khan, M. S. I.; Haider, J.; Saha, R. R. Yield and water use of onion under different irrigation schedules in Bangladesh. Japanese Journal of Tropical Agriculture, v.41, p.268-274, 1997.

Santa-Olalla, F. M.; Dominguez-Padilla, A.; Lopez, R. Production and quality of onion crop (Allium cepa L.) cultivated in semi-arid climate. Agricultural Water Management, v.68, p.77-89, 2004.
Santa-Olalla, F. M.; Valero, J. A. J.; Cortes, C. F. Growth and production of onion crop (Allium cepa L.) under different irrigation scheduling. European Journal of Agronomy, v.3, p.85-92, 1994.

Santos, S. R.; Pereira, G. M. Comportamento da alface tipo americana sob diferentes tensões de água no solo, em ambiente protegido. EngenhariaAgrícola, v.24, p.569-577, 2004.

Shock, C. C.; Feibert, E. B. G.; Saunders, L. D. Irrigation criteria for drip-irrigated onions. HortScience, v.35, p.63-66, 2000.

Souza, R. J.; Resende, G. M. Cultura da cebola. Lavras: UFLA, 2002. 115p. Texto Acadêmico n.21

Taiz, L.; Zeiger, E. Fisiologia vegetal. Porto Alegre: Artmed, 2004. 719p.

Vidigal, S. M.; Sediyama, M. A. N.; Pedrosa, M. W.; Santos, M. R. Produtividade de cebola em cultivo orgânico utilizando composto à base de dejetos de suínos. Horticultura Brasileira, v.28, p.168-173, 2010. 